\title{
Baller-Gerold syndrome
}

INSERM

\section{Source}

INSERM. (1999). Orphanet: an online rare disease and orphan drug data base. Baller-

Gerold syndrome. ORPHA:1225

Baller-Gerold syndrome is characterized by the association of coronal craniosynostosis

with radial ray anomalies (oligodactyly, aplasia or hypoplasia of the thumb, aplasia or hypoplasia of the radius). 